\title{
Adult Intussusception Presenting with Target Sign
}

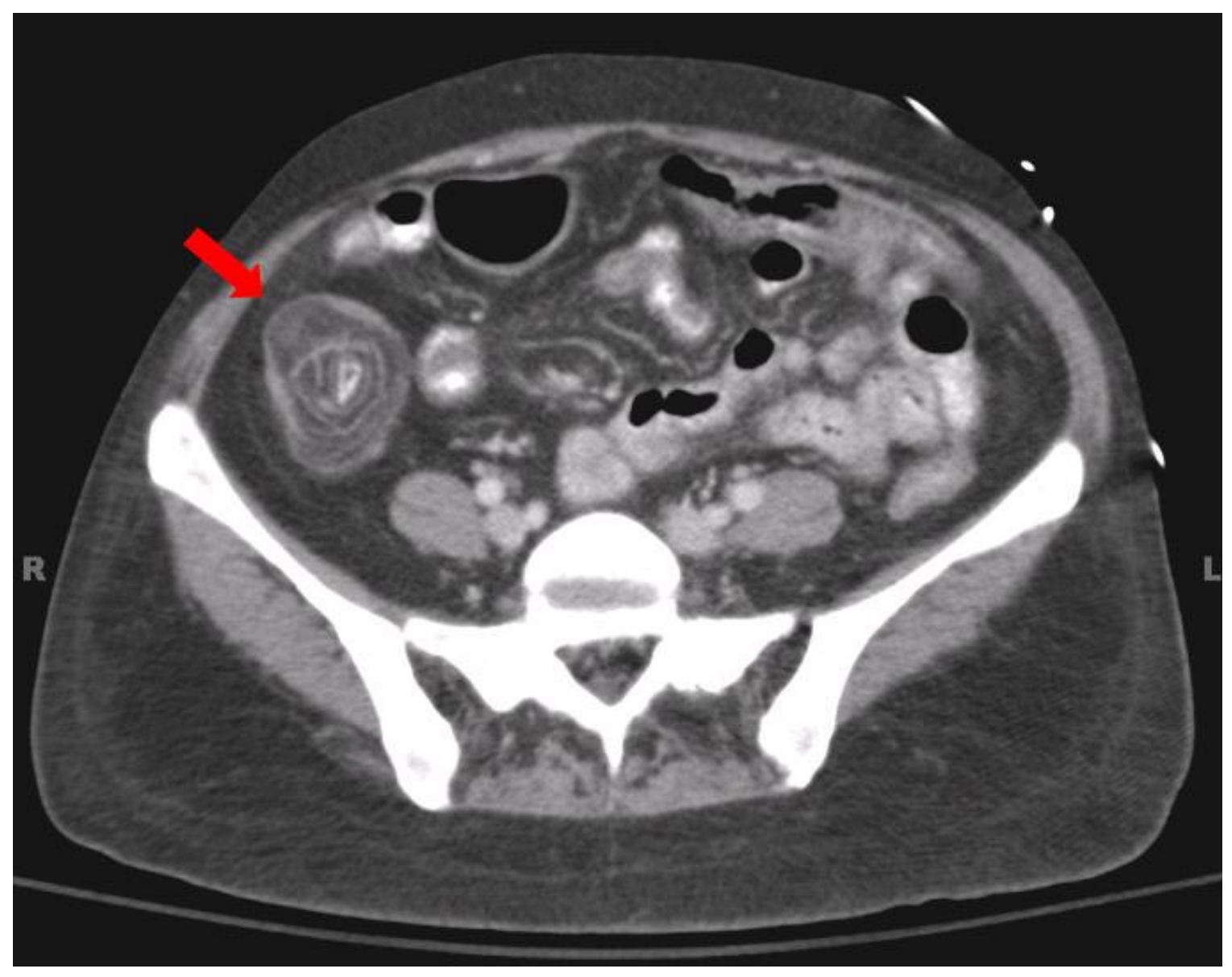

FIGURE. CT of the abdomen with target sign, suggesting ileocolic intussusception (see arrow).

Emmanuel C. Gorospe

Department of Medicine, Johns Hopkins Bayview Medical Center, Johns Hopkins University School of Medicine, Baltimore, MD

E-mail: egorosp1@jhmi.edu

Received September 20, 2008; Accepted November 14, 2008; Published November 22, 2008

KEYWORDS: intussusception, ileocolic, computed tomography 
Intussusception occurs when a proximal bowel segment telescopes into a contiguous distal portion. It is a rare condition in adults, occurring in less than $1 \%$ of all intestinal obstructions[1]. Spontaneous or idiopathic intussusception in adults is even rarer. Unlike in children, an underlying cause is present in $90 \%$ of cases due to intraluminal lesions, malignancy, adhesions, and postsurgical complications[2,3,4]. This abdominal CT is from a 48-year-old female who presented with a 2-day history of worsening rightsided abdominal pain, nausea, and loss of appetite. There was no previous abdominal surgery or other medical comorbidities. Her screening colonoscopy 4 months ago was unremarkable. The physical exam was significant for right-sided abdominal tenderness. The leukocyte count was $21,500 / \mu \mathrm{L}$ and lactic acid was $23 \mathrm{mg} / \mathrm{dL}$. The abdominal CT scan showed a classic "target" or "donut" sign, suggestive of ileocolic intussusception. The patient underwent partial right colon resection with end-to-end anastomosis. The resected small bowel and colon segments showed ischemic changes only. The patient was discharged without complications. Abdominal CT is the imaging of choice[5]. When diagnosed, surgical resection is preferred compared to reduction in view of multiple possible pathology[3].

\section{REFERENCES}

1. Triantopoulou, C., Vassilaki, A., Filippou, D., Velonakis, S., Dervenis, C., and Koulentianos, E. (2004) Adult ileocolic intussusception secondary to a submucosal cecal lipoma. Abdom. Imaging 29, 426-428.

2. Weilbaecher, D., Bolin, J.A., Hearn, D., and Ogden, W., 2nd (1971) Intussusception in adults. Review of 160 cases. Am. J. Surg. 121, 531-535.

3. Yalamarthi, S. and Smith, R.C. (2005) Adult intussusception: case reports and review of literature. Postgrad. Med. J. 81, 174-177.

4. Jabar, M.F., Prasannan, S., and Gul, Y.A. (2005) Adult intussusception secondary to inflammatory polyps. Asian J. Surg. 28, 58-61.

5. Takeuchi, K., Tsuzuki, Y., Ando, T., Sekihara, M., Hara, T., Kori, T., and Kuwano, H. (2003) The diagnosis and treatment of adult intussusception. J. Clin. Gastroenterol. 36, 18-21.

\section{This article should be cited as follows:}

Gorospe, E.C. (2008) Adult intussusception presenting with target sign. TheScientificWorldJOURNAL 8, 1154-1155. DOI 10.1100/tsw.2008.150. 


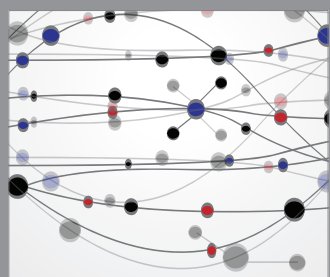

The Scientific World Journal
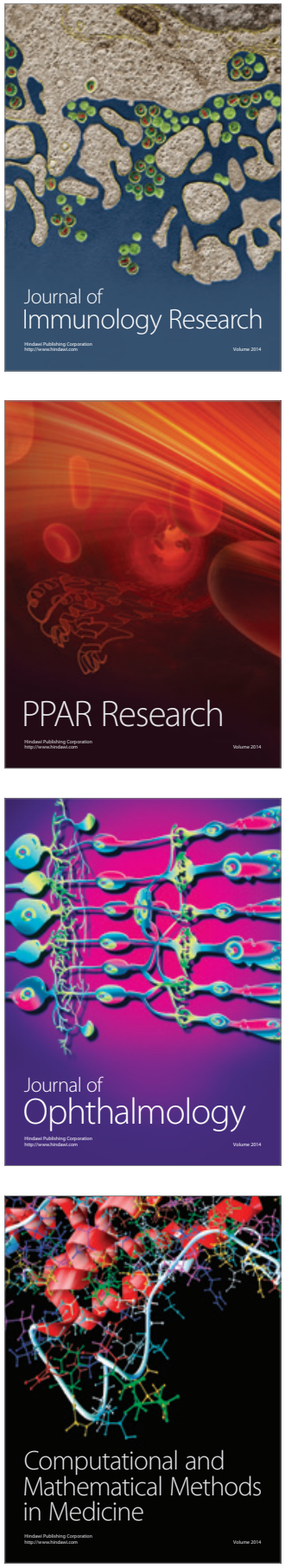

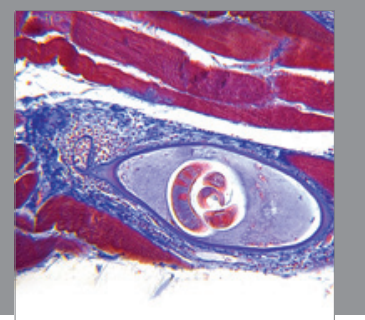

Gastroenterology

Research and Practice
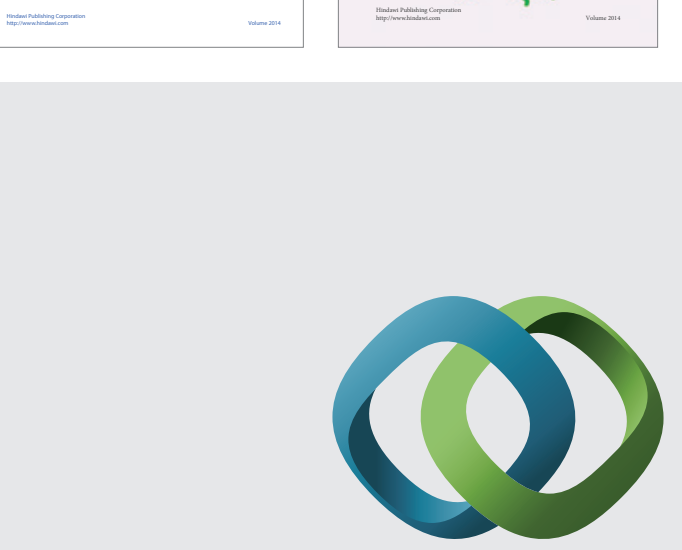

\section{Hindawi}

Submit your manuscripts at

http://www.hindawi.com
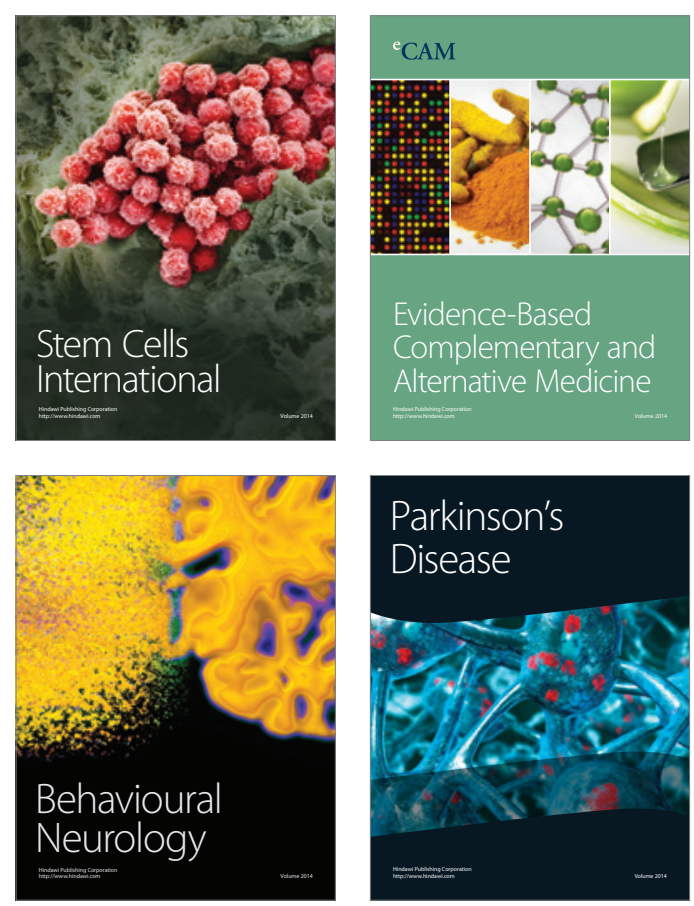

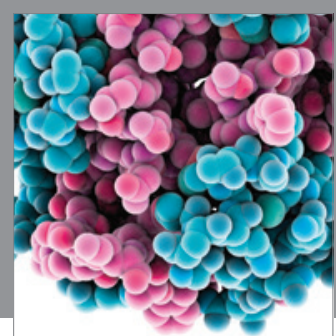

Journal of
Diabetes Research

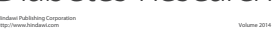

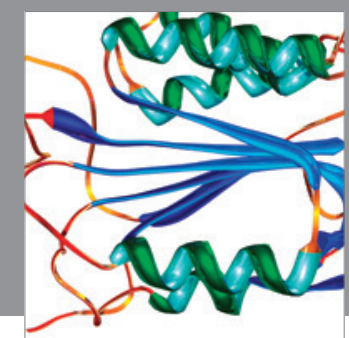

Disease Markers
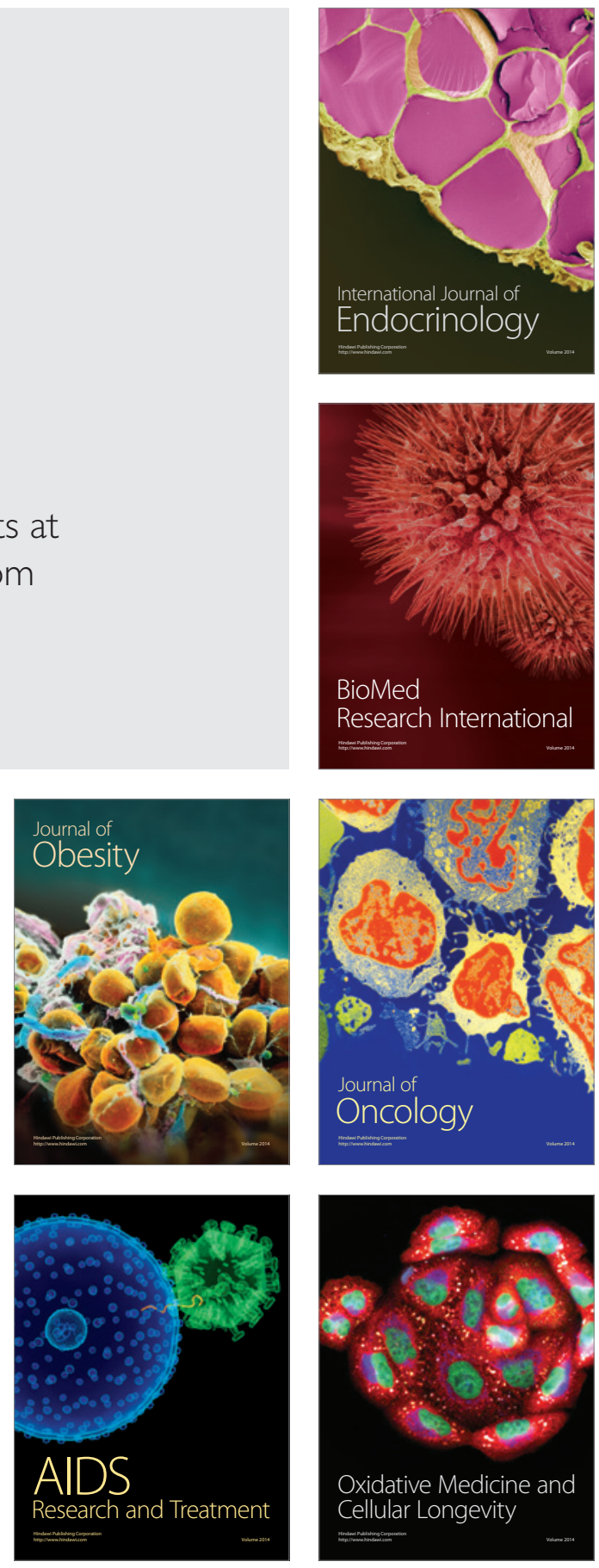